\title{
Strategi Pengembangan Wisata Kuliner Waroeng Pohon Yogyakarta Berbasis Ecotourism
}

\author{
Candra Ratna Gupita \\ Program Studi Ilmu Komunikasi Universitas Muhammadiyah Yogyakarta, Yogyakarta, Indonesia \\ Email: candraaratna@gmail,com
}

\begin{abstract}
Waroeng Pohon Restaurant is a company engaged in the field of culinary in Yogyakarta culinary with traditional culinary of Central Java. This study analyzes the strategy of developing ecotourism-based Waroeng Pohon Yogyakarta culinary tourism in attracting visitors and giving visitors awareness to always love the environment. The tight competition in the culinary field makes Waroeng Pohon must have a strong strategy in order to survive and continue to exist from other culinary delights. Waroeng Pohon has a development strategy that is carried out aimed at introducing, promoting, maintaining, developing products to the community so that they can be interested in visiting Waroeng Pohon. The research method used in this research is descriptive using a case study strategy. Data collection is conducted by interview, observation, and documentation. Analysis technique which is done by collecting data, analyzing data and draw conclusion. The results of this study indicate Waroeng Pohon has a mission to be able to preserve the environment for all employees and visitors. The restaurant environment maintains environmental sustainability, with buildings that adapt to the environment. This is the Waroeng Pohon branding that sets it apart from other restaurants. This branding is the advantage of Waroeng Pohon compared to its competitors.
\end{abstract}

Keywords : Ecotourism, Tourism, Culinary, Waroeng Pohon

\begin{abstract}
ABSTRAK
Rumah Makan Waroeng Pohon merupakan usaha yang bergerak di bidang kuliner di Kota Yogyakarta dengan menu masakan tradisional Jawa. Penelitian ini menganalisis tentang strategi pengembangan wisata kuliner Waroeng Pohon berbasis ecotourism dalam menarik minat pengunjung dan memberikan kesadaran pengunjung agar selalu mencintai lingkungan. Sebagai salah satu pelaku usaha yang bergerak dibidang Rumah Makan Waroeng Pohon tentu memiliki strategi yang kuat agar dapat bertahan dan tetap eksis dari kuliner-kuliner yang lain. Waroeng Pohon memiliki strategi pengembangan yang dilakukan bertujuan untuk mengenalkan, mempromosikan, mempertahankan, mengembangkan produk kepada masyarakat agar dapat tertarik untuk mendatangi Waroeng Pohon. Metode penelitian yang digunakan dalam penelitian ini adalah deskriptif dengan menggunakan strategi studi kasus. Pengumpulan data dilakukan dengan wawancara, observasi, dan dokumentasi. Teknik analisis yang dilakukan dengan mengumpulkan data, menganalisis data dan menarik kesimpulan. Hasil penelitian ini memperlihatkan bahwa Waroeng Pohon memiliki misi untuk dapat melestarikan lingkungan bagi seluruh karyawan dan pengunjung. Lingkungan rumah makan yang menjaga kelestarian lingkungan, dengan bangunan yang beradaptasi dengan lingkungan. Ini adalah branding Waroeng Pohon yang membedakan dari rumah makan lainnya. Branding ini adalah keunggulan Waroeng Pohon dibandingkan dengan pesaingnya.
\end{abstract}

Kata kunci: Strategi pengembangan, Baruan pengembangan, Waroeng Pohon. 


\section{Pendahuluan}

Rumah makan merupakan peluang bisnis yang sangat berpotensial. Perkembangan zaman saat ini memungkinkan orang untuk mendapatkan pelayanan yang lebih lengkap untuk mencukupi kebutuhan hidupnya. Fungsi dari rumah makan yang awalnya hanya untuk tempat makan dan beristirahat kini pun menjadi sangat berkembang. Saat ini rumah makan menjadi bagian dari trend dan gaya hidup. Rumah makan kini sudah menjadi tempat yang asik untuk nongkrong, foto, pesta, reuni dan lain sebagainya. Usaha rumah makan juga dapat menjadi sarana munculnya ikon dari kepariwisataan. Karena dengan usaha rumah makan sekarang ini tidak hanya memanjakan lidah saja selain itu juga memanjakan mata, karena rumah makan di era globalisasi sekarang ini rumah makan yang hanya menyuguhkan makanan khas daerah itu pasti akan tertinggal.

Menurut BPS (Badan Pusat Statistik) Daerah Istimewa Yogyakarta bahwa bisnis industri rumah makan di Yogyakarta pertumbuhannya semakin pesat, wilayah Yogyakarta sendiri merupakan kawasan potensial untuk bisnis di bidang kuliner. Sebelum tahun 1981 persentase yang diperoleh hanya sebesar 2,63\%, tahun 1981-1990 sebesar 7,89\%, tahun 1991-1998 meningkat menjadi 10,53\% dan pada tahun 1999-2009 peningkatan persentase semakin bertambah $30 \%$ yaitu sebesar 39,47\% dan setelah 2009 juga sebesar $39,47 \%$. Usaha tersebut merupakan usaha rumah makan yang tercatat wajib pajak, dan lebih banyak lagi usaha-usaha yang belum tercatat yang masih pada tahap berkembang. Untuk kawasan rumah makan Provinsi Daerah Istimewa Yogyakarta pada kawasan wisata ada $26,32 \%$, dan untuk kawasan perkantoran atau perkotaan sebesar $42,11 \%$ dan lainnya sebesar 31,58\% (sumber : Stastistik Restoran Rumah Makan 2015).

Oleh karena itu semakin pesat berkembangnya bisnis usaha kuliner maka persaingan rumah makan akan semakin ketat. Hal tersebut adalah tantangan bagi rumah makan untuk menerapkan strategi pengembangan agar memperkuat citra rumah makan tersebut pada konsumennya. Dengan bekal visi dan misi yang pasti, bagi pemilik rumah makan tentu telah berpikir panjang dan kedepan tentang bagaimana mengemas produk andalan yang berkualitas, menarik, dan disenangi oleh konsumennya. Di tengah ketatnya persaingan usaha rumah makan saat ini, maka setiap rumah makan harus memiliki strategi yang kuat untuk dapat mempertahankan kualitas produk yang mereka miliki. Strategi merupakan alat untuk mencapai tujuan. Strategi dalam suatu dunia usaha sangatlah dibutuhkan untuk pencapaian visi dan misi yang sudah diterapkan oleh 
perusahaan itu, maupun untuk pencapaian sasaran atau tujuannya, baik untuk tujuan jangka pendek maupun jangka panjang. Strategi adalah seni dimana melibatkan kemampuan pikiran untuk membawa semua sumber daya yang tersedia dalam mencapai tujuan dengan memperoleh keuntungan yang maksimal dan efisien (Cangara, 2013, p. 61)

Strategi saat ini sudah menjadi perbincangan yang sangat umum dan didefinisikan sedemikian rupa untuk satu kepentingan perusahaan atau organisasi guna mencapai tujuan. Makna yang tergantung di dalam strategi adalah sekumpulan tindakan yang dirancang untuk menyesuaikan antara kompetensi perusahaan dan tuntunan eksternal pada satu industri. Keharusan menyusun strategi adalah untuk mencapai tujuan perusahaan, baik pada jangka menengah maupun jangka panjang. Strategi akan menjamin perusahaan dapat bertahan atau berkembang pada masa yang akan dating (Hamali, 2016, p. 17).

Mulyana (2018, pp. 2-3) telah melakukan penelitian tentang Strategi Pengembangan Kawasan Wisata Kuliner di Kalibawang dan Samigaluh Kulonprogo mereka menyebutkan bahwa kawasan pariwisata dikembangkan dengan meningkatkan peran serta pemerintah, masyarakat dan swasta dalam pembangunan.
Hal ini berkaitan dengan pengembangan sarana dan prasarana seperti akomodasi, restoran, usaha rekreasi dan hiburan umum. Dengan pengembangan wisata kuliner ini menjanjikan peluang bisnis yang cukup lumayan. Apalagi jika pemasaran kawasan kuliner ini sudah meluas ke turis mancanegara. Berdasarkan hasil penelitian yang dilakukan dapat ditarik kesimpulan bahwa strategi pengembangan wisata kulinernya melalui makanan khas dan minuman khas dari Samigalih yaitu gebleg dan minum teh.

Sementara itu (Sherdianto \& Anom, 2019, p. 350) melakukan penelitian sejenis dengan meneliti tentang Pengembangan Waroeng Semawis dalam Mendukung Wisata Kuliner Di Kota Semarang Provinsi Jawa Tengah menyatakan bahwa fokus pengembangan di Waroeng Semawis hanya sebatas pada bagaimana meningkatkan kualitas wisatawan tanpa mencoba memperbaiki kualitas wisata yang ada. Tren saat ini sesungguhnya membuat wisata kuliner naik daun karena tidak afdol apabila wisatawan mengunjungi sebuah destinasi tersebut dan juga di Waroeng Semawis ini terdapat berbagai macam makanan khas dari Semarang.

Asumsi wisata kuliner ditunjukkan ketika rumah makan tersebut memiliki kekhasan dari makanan dan minumannya. Berbeda dengan penelitian terdahulu yang 
mengambil objek penelitian pada wisata kuliner yang hanya memiliki kekhasan dari makanan dan minumannya yang berada di kawasan tersebut, penelitian ini akan membahas tentang pengembangan wisata kuliner yang tidak hanya memberikan kekhasan makanan dan minuman di daerah tersebut Waroeng Pohon juga berupaya melakukan pelestarian lingkungan hidup.

Ecotourism adalah bentuk pariwisata yang melibatkan kunjungan yang rapuh, murni, dan relatif tidak terganggu daerah alami, dimaksudkan sebagai dampak rendah dan sering alternatif skala kecil untuk pariwisata komersial (massa) standar. Tujuannya mungkin untuk mendidik pelancong, untuk menyediakan dana untuk konservasi ekologis, untuk secara langsung bermanfaat bagi pembangunan ekonomi dan pemberdayaan politik masyarakat lokal, atau untuk menumbuhkan rasa hormat terhadap perbedaan budaya dan hak asasi manusia. Sejak 1980-an ecotourism telah dianggap kritis Berusaha keras oleh pencinta lingkungan, sehingga generasi mendatang dapat mengalami tujuan relatif tidak tersentuh oleh intervensi manusia. Beberapa program universitas digunakan deskripsi ini sebagai definisi kerja ekowisata (Lucius Walker, 2017, p. 38).

Menurut (Fennel, 1999, p. 43) ecotourism merupakan wisata berbasis alam yang berkelanjutan dengan fokus pengalaman dan pendidikan tentang alam, dikelola dengan sistem pengelolaan tertentu dan memberi dampak negatif paling rendah terhadap lingkungan, tidak bersifat konsumtif dan berorientasi pada lokal (dalam hal kontrol, manfaat yang dapat diambil darikegiatan usaha).

$$
\text { Sedangkan menurut World }
$$

Conservation Union (1996) menyebutkan bahwa ekowisata adalah perjalanan bertanggung jawab secara ekologis, mengunjungi daerah yang masih asli (pristine) untuk menikmati dan menghargai keindahan alam (termasuk kebudayaan lokal) dan mempromosikan konservasi. Wood (2002) memberikan pengertian ekowisata sebagai kegiatan wisata bertanggung jawab yang berbasis utama pada kegiatan wisata alam, dengan mengikutsertakan pula sebagian kegiatan wisata pedesaan dan wisata budaya. Selain itu, ecotourism juga merupakan kegiatan wisata yang dilakukan dalam skala kecil baik pengunjung maupun pengelola wisata. Konsep pembangunan pariwisata yang memperhatikan adanya keseimbangan antara aspek kelestarian alam dan ekonomi adalah konsep ekowisata dan wisata minat khusus (Arida, 2017, p. 16).

Penelitian ini bertujuan untuk mengetahui dan memahami bagaimana strategi 
pengembangan wisata kuliner berbasis ecotourism di rumah makan Waroeng Pohon.

\section{Metode Penelitian}

Penelitian ini berada pada wilayah deskriptif kualitatif dengan metode studi kasus. Bogda dan Taylor (Moleong, Lexy, 2014, p. 4) mendefinisikan metodologi kualitatif sebagai prosedur penelitian yang menghasilkan data deskriptif berupa kata-kata tertulis atau lisan dari orang-orang dan perilaku yang dapat diamati. Menurut Yin (Ishak et al., 2011, p. 205) (Ishak et al., 2011, p. 205)Penelitian dengan menggunakan pendekatan studi kasus menginvestigasikan peristiwa competitor yang nyata terjadi dalam kehidupan dan antara peristiwa dengan konteks tidak dapat dipisahkan. Pada penelitian ini, objek penelitian ini difokuskan pada strategi pengembangan wisata kuliner berbasis ecoturism yang dilakukan rumah makan Waroeng Pohon. Teknik pengumpulan data yang dilakukan peneliti adalah untuk menjadi alat ukur dan bukti penelitian. Adapun teknikteknik yang digunakan adalah dengan wawancara mendalam, observasi dan dokumen.

Teknik analisis data kualitatif adalah upaya yang dilakukan dengan jalan bekerja dengan data, mengorganisasikan data, memilah-memilahnya menjadi satuan yang dapat dikelola, mensintesiskannya, mencari dan menemukan pola, menemukan apa yang penting dana pa yang dipelajari, dan memutuskan apa yang dapat diceritakan pada orang lain (Moleong, 2008, p. 248).

Menurut Miles dan Huberman (1992, p. 20), terdapat tiga analisis data kualitatif, yaitu:

1. Reduksi Data

Reduksi data adalah salah satu teknik analisis data kualitatif. Reduksi data merupakan bentuk analisis yang menjelaskan, menggolongkan, menggunakan, mengarahkan, membuang yang tidak perlu dan mengorganisasi data sedemikian rupa sehingga kesimpulan akhir dapat dambil.

2. Penyajian Data

Penyajian data adalah kegiatan penyusunan informasi yang didapat peneliti sehingga memunculkan adanya kemungkinan penarikan kesimpulan. Teknik analisis ini diperlukan agar peneliti dapat dengan mudah memahami dan melihat gambaran secara umum tentang apa yang terjadi dalam penelitian yang telah dilakukan atau hasil dari penelitian itu sehingga dapat menentukan langkahlangkah selanjutnya.

3. Penarikan kesimpulan

Penarikan kesimpulan dilakukan pada saat penelitian berlangsung. Proses ini terjadi 
ketika peneliti mengetahui apa yang terjadi ketika melakukan penelitian. Melalui penarikan kesimpulan dapat diketahui langkah-langkah selanjutnya yang akan ditempuh oleh peneliti.

\section{Hasil Penelitian dan Pembahasan}

Ecotourism merupakan kegiatan meminimalisir kerusakan lingkungan, menghormati lingkungan, menghargai lingkungan sehingga memiliki pengunjung dengan dampat negatif yang rendah. Danto Susanto, pemilik Waroeng Pohon, mengatakan:

\begin{abstract}
"Bahwa Waroeng Pohon ini dapat meminimalkan kerusakan lingkungan yang terjadi, menghormati lingkungan, mengurangi pemanasan global, melestarikan lingkungan. Menurut saya rumah makan jaman sekarang kurang memperhatikan dari dampak pemanasan global. Kebanyakan rumah makan yang ada di Jogja itu menampilkan sesuatu tema yang kekinian. Misalnya dengan gaya arsitektur minimalis atau open space tetapi jarang rumah makan di Jogja yang berusaha mengintegrasikan alam artinya kalau orang bangun rumah makan itu biasanya pohon menyesuaikan dengan bangunan kalo dia dianggap menganggu maka dia akan ditebang sedangkan waroeng pohon ini sebelumnya memang lahan kosong yang ditanami berbagai jenis pohon kemudian bangunan menyesuaikan pohon tersebut". (Hasil wawancara, 25 Januari 2020).
\end{abstract}

Penjelasan mengenai tentang ekowisata yang diterapkan Waroeng Pohon dimana banyaknya pepohonan yang rindang tidak asal tebang, karena bangunan tersebut yang menyesuaikan pohon yang ada.

Memikirkan konsep yang detail dan unik akan menghasilkan tempat yang memanjakan mata. Selain bangunan yang unik pepohonan yang rindang juga mampu memikat orang-orang untuk berkunjung. Danto Susanto mengatakan:

\begin{abstract}
"Awalnya saya memikirkan konsep alam ini karena keinginan saya melestarikan lingkungan, mengurangi pemanasan global dan saya juga kebetulan menyukai tanaman. Saya juga selalu menekankan kepada karyawan agar selalu mencintai alam, kebersihan lingkungan dan merawat pohon. Konsumen juga jadi segan ketika berkunjung di Waroeng Pohon yang ingin membuang sampah sembarangan juga pasti merasa tidak enak, coba aja kalau kita berada di rumah makan yang jorok pasti dengan seenaknya akan membuang sampah sembarangan. Kita mampu memberikan pengalaman positif pada para pengunjung agar tetap menjaga kebersihan dan mencintai lingkungan". (Hasil wawancara, 25 Januari 2020).
\end{abstract}

Memberikan efek positif terhadap karyawan juga pada seluruh pengunjung agar selalu tetap menjaga kebersihan dan mencintai lingkungan hidup. Terdapat beberapa hal yang layak dijadikan pertimbangan dalam menetapkan berbagai macam potensi kuliner khas pada suatu daerah, salah satunya diutarakan oleh Wolf dalam Suriani (2009, p. 13) bahwa beberapa hal yang menjadi pertimbangan atau penilaian wisatawan untuk mengkonsumsi masakan lokal yaitu harga yang terjangkau, citarasa yang khas, merek (trademark), kemasan lokal, kualitas makanan, porsi yang sesuai harga, lokasi yang autentik serta fasilitas fisik bangunan yang khas.

Wisata kuliner yang berasal dari istilah food tourism didefinisikan sebagai sebuah kunjungan ke suatu tempat yang merupakan 
produsen pertama maupun produsen kedua dari suatu bahan makanan, festival makanan, restoran, dan lokasi-lokasi khusus untuk mencoba rasa dari makanana dan atau juga untuk memperoleh pengalaman yang didapat dari makanan khas suatu daerah merupakan motivasi utama seseorang untuk melakukan perjalanan wisata (Hall et al., 2003, pp. 9-10).

Waroeng Pohon ini membuktikan bahwa menjadi wisata kuliner ini dengan menu makanannya yaitu khas tradisional dari Jawa. Menu-menu yang disediakan kebanyakan memang menu tradisional yaitu ada sego sarang ayam ingkung, ayam atau ikan dengan bumbu khas Jawa meliputi pecel, bumbu rujak, dabudabu. Menu minumannya juga tradisional khas Jawa yaitu ada wedang uwuh, jahe, the poci, gula asem, gula asem kencur, wedang tape, dan wedang badeg. Cara penyajiannya juga masih tradisional yaitu dengan anyaman daun kelapa yang dibentuk seperti sarang burung. Kemudian terdapat dari tempatnya yang masih kental dengan budaya Jawa terdapat barangbarang kuno dan tempat pendopo yang merupakan peninggalan bangunan khas Yogyakarta. Waroeng Pohon ini juga terkenal dengan harganya yang terjangkau dan memiliki cita rasa yang enak sehingga memberikan kesan para wisatawan yang berkunjung untuk mencicipi salah satu wisata kuliner yang ada di Yogyakarta ini. Wisata kuliner Waroeng
Pohon ini termasuk yang berhasil untuk didaerah Bantul sendiri karena setiap taunnya membludak wisatawan dari luar kota bahkan dari luar negeri dan termasuk para artis tanah air yang sudah banyak berkunjung ditempat ini. Berarti Waroeng Pohon ini sudah menjadi salah satu wisata kuliner yang eksis yang menjadi tujuan mereka untuk berkunjung di Yogyakarta.

Menurut Fandeli (2002) melalui ecotourism, wisatawan dan seluruh komponen yang terkait dengan penyelenggaraan wisata diajak untuk lebih peka terhadap masalah lingkungan dan sosial sehingga diharapkan sumberdaya alam tetap lestari dan wisatawan mempunyai apresiasi lingkungan yang tinggi. Di samping itu, masyarakat di sekitar objek pariwisata memperoleh keuntungan dari penyelenggaraan pariwisata, karena wisatawan ekowisata yang datang umumnya mempunyai tujuan mencari kesempatan untuk bersatu dengan alam dan budaya lokal dengan menjauhi hiruk-pikuk suasana perkotaan (Arida, 2017, p. 16).

Definisi ecotourism dapat ditinjau dari tiga unsur utamanya yaitu nature-based, educative dan sustainable management. Nature-based berkaitan dengan keberadaan flora dan fauna suatu kawasan yang dapat diasosiasikan dengan lingkungan yang telah dimodifikasi sebelumnya. Kegiatan ecoturism 
hendaknya memberi dampak negatif sekecil mungkin terhadap alam. Unsur educative terkait dengan pentingnya informasi untuk mendukung pengalaman dan pembelajaran dalam berwisata yang dapat membantu wisatawan memahami kawasan yang mereka kunjungi. Pengelolaan suatu kawasan ecotourism harus mengacu pada keberlanjutan lingkungan sebagai bagian dari pertimbangan dan tanggung jawab ke arah kelestarian lingkungan di masa dating (Beeton, 1998, p. 9).

Hijriati dan Mardiana (2015, p. 154) telah melakukan penelitian tentang Pengaruh Ekowisata Berbasis Masyarakat Terhadap Perubahan Kondisi Ekologi, Sosial dan Ekonomi di Kampung Batusuhunan, Sukabumi mereka menyebutkan bahwa aspek lingkungan yang alamiah dalam ekowisata merupakan aspek utama ciri khas ekowisata. Manusia hidup bergantung dengan lingkungan, begitu pula lingkungan yang membutuhkan perawatan manusia. Keberlanjutan ekowisata juga bergantung pada lingkungan, maka masyarakat diharapkan dapat terlibat untuk merawatnya.

Menurut Supardi (2003, p. 4) peduli terhadap lingkungan berarti ikut melestarian lingkungan hidup dengan sebaik - baiknya, bisa dengan cara memmelihara, mengelola, memulihkan, serta menjaga lingkungan hidup. Pedoman yang harus diperhatikan dalam kepedulian atau pelestarian lingkungan antara lain, menghindarkan dan menyelamatkan sumber bumi dari pencemaran dan kerusakan, kemudian menghindari tindakan - tindakan yang dapat menimbulkan pencemaran, pencemaran merusak kesehatan dan lingkungan, selanjutnya pemanfaatkan sumber daya alam yang reneuble (yang tidak dapat diganti) dengan sebaik - baiknya. Terakhir, adalah mampu memelihara dan memperbaiki lingkungan untuk generasi mendatang.

Waroeng Pohon ini mampu meminimalisir kerusakan lingkungan. Menurut owner Waroeng Pohon sudah menerapkan ecotourism ini dengan cara menghormati lingkungan dengan menekankan kepada seluruh karyawan untuk selalu merawat dan mencintai pepohonan dengan cara setiap sehari sekali menyiram air pada setiap pohon, memotong daun dengan rapi, membersihkan ranting pohon yang sudah mati. Sehingga pohon dan tanaman yang ada disana terawat dengan baik dan dapat memberikan lingkungan yang asri kemudian juga memberikan kesejukan dari udaranya.

Kemudian, owner selalu menekankan terhadap seluruh karyawannya untuk kebersihan harus selalu dijaga dengan sebaik mungkin. Membersihkan daun yang berjatuhan maupun sampah-sampah yang ada dan untuk air dari cucian kotor juga dipisahkan dan memiliki wadah sendiri, begitu pula sampah 
yang dipisahkan baik organik maupun nonorganik. Mampu memberikan efek yang positif bagi seluruh karyawan dan juga pada konsumen yang datang. Mereka juga sadar akan lingkungan karena melihat dari lingkungan yang bersih dan asri dari Waroeng Pohon. Misalnya, mereka tidak akan membuang sampah dengan sembarangan pada saat berada di tempat itu tetapi jika tempat itu kotor pasti akan memberikan efek negatif karena pasti mereka akan membuang sampah dengan sembarangan. Para pengunjung yang datang ke Waroeng Pohon ini selalu menjaga kebersihan pada saat mengunjunginya dan mereka juga mendapat pikiran untuk dapat melestarikan lingkungan dimana saja contohnya selalu menjaga dan merawat tanaman yang ada di rumahnya dan sekitarnya. Memberikan kesadaran kepada pengunjungnya agar selalu mencintai lingkungan agar memberikan dampak yang positif di masa sekarang dan masa depan. Karena lingkungan dan manusia merupakan satu kesatuan ekologis. Dengan ini keberlangsungan hidup masyarakat akan seimbang. Waroeng Pohon ingin menyadarkan kepada pengunjungnya agar memiliki sikap untuk ikut serta melestarikan lingkungan karena minimnya kesadaran masyarakat sekarang mengenai lingkungan. Ecotourism yang dilakukan harus selalu ditingkatkan dan harus dikembangka agar mampu memperbaiki kondisi lingkungan yang rusak.

\section{Penutup}

Berdasarkan pembahasan di atas, strategi pengembangan wisata kuliner Waroeng Pohon berbasis ecotourism yaitu dengan meminimalisir kerusakan lingkungan dalam proses pembangunan dan melakukan perawatan lingkungan dengan teratur. Waroeng Pohon menekankan upaya menghormati lingkungan dengan cara menekankan kepada seluruh karyawan agar merawat tanaman yang ada dan selalu menjaga kebersihan agar memberikan dampak yang positif bagi siapapun terutama untuk pengunjung juga. Wisatawan juga diedukasi agar mampu berpartisipasi karena jika tempatnya sudah menerapkan keasrian pelestarian lingkungan namun pengunjungnya malah merusak dan mengotori sama saja dia tidak menerapkan ecotourism ini. Jadi, adanya kesadaran dari seluruh pihak akan membangun lingkungan yang baik dan terjaga hingga masa mendatang.

\section{Daftar Pustaka}

Arida, I. N. S. (2017). Ekowisata Pengembangan, Partisipasi Lokal, dan Tantangan Ekowisata. Denpasar: Cakra Press.

Beeton, S. (1998). Ecoturism: A Practical Guide for Rural Communities. Australia: Brown Prior Anderson. 
Cangara, H. (2013). Perencanaan dan Strategi Komunikasi. Jakarta: Raja grafindo.

Fennel, D. A. (1999). Ecotourism: An Introduction. London: Routledge.

Hall, C. M., Sharples, L., Mitchell, R., Macionis, N., \& Cambourne, B. (2003). Food tourism around the world. Food Tourism Around The World, 1-373. https://doi.org/10.4324/9780080477862

Hamali, A. Y. (2016). Pemahaman Strategi Bisnis \& Kewirausahaan. Jakarta: Prenada Media.

Hijriati, E., \& Mardiana, R. (2015). Pengaruh Ekowisata Berbasis Masyarakat Terhadap Perubahan Kondisi Ekologi, Sosial Dan Ekonomi Di Kampung Batusuhunan, Sukabumi. Sodality: Jurnal Sosiologi Pedesaan, 2(3), 146-159. https://doi.org/10.22500/sodality.v2i3.9422

Ishak, A., Junaedi, F., Budi, H. S., \& Prabowo, A. (2011). Mix Methodology Dalam Penelitian Komunikasi (Dilengkapi Dengan Aplikasi metode Penelitian). Yogyakarta: Mata Padi Pressindo.

Lucius Walker. (2017). Tourism and Hospitality Management. New York: Library Press.

Miles, M. B., \& Huberman, A. M. (1992). Analisis data kualitatif: buku sumber tentang metode metode baru penerjemah, Tjetjep Rohendi; pendamping, Mulyarto. Jakarta: Penerbit Universitas Indonesia (UI-Press).

Moleong, Lexy, J. (2014). Metode Penelitian Kualitatif, Edisi Revisi. Bandung: PT Remaja Rosdakarya.

Moleong, L. J. (2008). Metode Penelitian Kualitatif (Revisi). Bandung: PT Remaja Rosdakarya.

Mulyana, Y. (2018). Yayan Mulyana dan Yulianto: Strategi Pengembangan Kawasan Wisata Kuliner di Kalibawang dan Samingaluh Kulonprogo Yogyakarta. Manajemen Resort Dan Leisure, 1. 15 , $1-10$. http://ejournal.upi.edu/index.php/jurel/article/vie w/11151

Sherdianto, G., \& Anom, I. P. (2019). Pengembangan Waroeng Semawis Dalam Mendukung Wisata Kuliner Di Kota Semarang Provinsi Jawa Tengah. Jurnal Destinasi Pariwisata, 6(2), 350. https://doi.org/10.24843/jdepar.2018.v06.i02.p23
Supardi, I. (2003). Lingkungan Hidup \& Kelestariannya (2nd ed.). Bandung: PT. Alumni.

Suriani, N. M. (2009). Seni Kuliner Bali Sebagai Salah Satu Daya Tarik Wisata Studi Kasus Di Warung Babi Guling Ibu Oka Di Kelurahan Ubud, Gianyar, Bali. Universitas Udayana. 